\title{
Flecked Calcifications in Scalp Tumors: Two Cases of Giant Ulcerated Trichilemmal Cysts
}

\author{
Prasad Krishnan $^{1}{ }^{10} \quad$ Abhijit Ray $^{1}$ \\ ${ }^{1}$ Department of Neurosurgery, National Neurosciences Centre, \\ Peerless Hospital, Kolkata, West Bengal, India \\ J Neurosci Rural Pract 2022;13:161-163.
}

\begin{abstract}
Address for correspondence Prasad Krishnan, MS, MCh, Department of Neurosurgery, National Neurosciences Centre, Peerless Hospital Campus, 2nd Floor, 360, Panchasayar Garia 700094, Kolkata, West Bengal, India (e-mail: prasad.krishnan@rediffmail.com).
\end{abstract}

\section{Abstract \\ Keywords \\ - calcification \\ - scalp tumors \\ - trichilemmal cysts}

In the article, the classical radiological findings in trichilemmal cysts of the scalp are described.
A 58-year-old patient presented with progressively increasing scalp swelling behind the vertex for past 5 years' duration. The lesion was lobulated, ulcerated at the dome, and approximately $8 \mathrm{~cm} \times 6 \mathrm{~cm} \times 6 \mathrm{~cm}$ in size (-Fig. 1A, B). Anteroposterior skiagrams showed a soft tissue scalp mass with specs of calcification inside it (-Fig. 2A) while computed tomography (CT) scans of brain showed a het- erogeneously hypodense soft tissue area within the scalp with multiple areas of calcification with no calvarial breach (-Fig. 2B-E). The patient underwent excision and primary closure by advancement of the opposing edges after undermining skin under scalp block (- Fig. 1C). Histopathological examination was suggestive of a trichilemmal cyst.

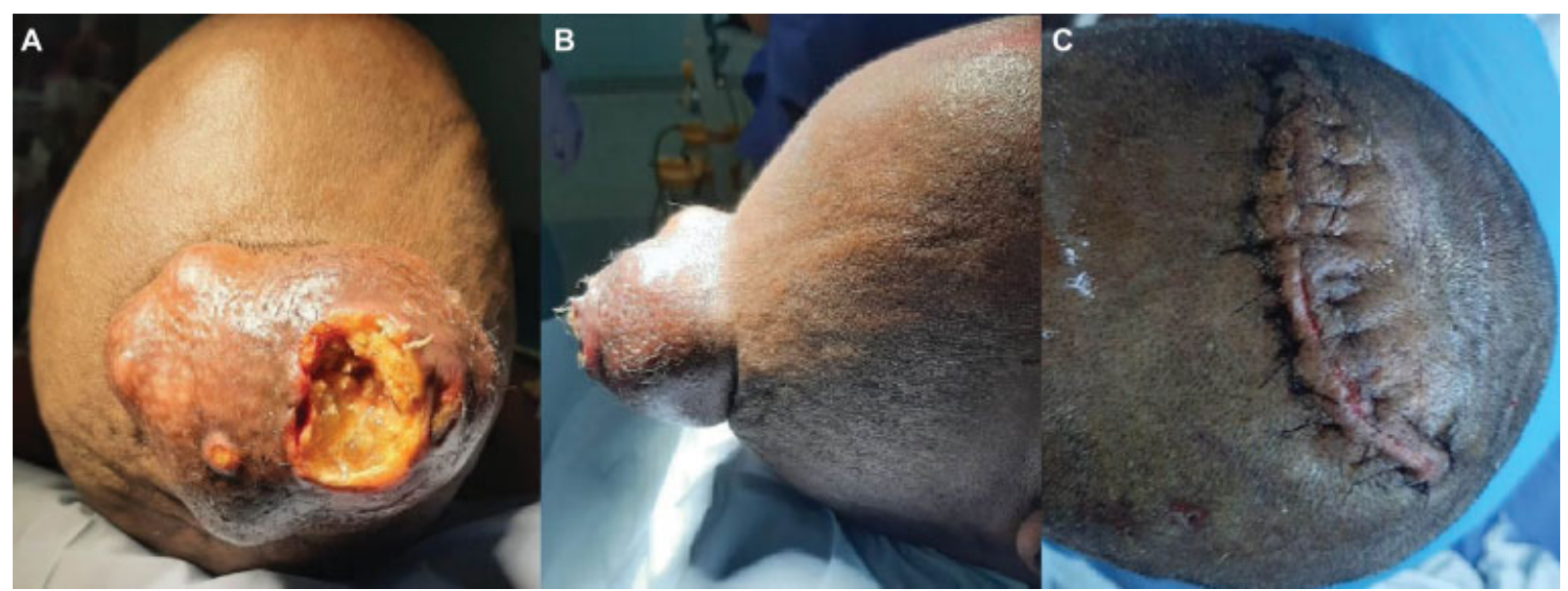

Fig. 1 Clinical photographs preoperative (A, B) of the scalp lesion showing a large lobulated mass with ulceration at the summit and postoperative image $(\mathrm{C})$ after excision of the mass and closure.

published online January 5, 2022
DOI https://doi.org/

10.1055/s-0041-1741486. ISSN 0976-3147. (c) 2022. Association for Helping Neurosurgical Sick People. All rights reserved.

This is an open access article published by Thieme under the terms of the Creative Commons Attribution-NonDerivative-NonCommercial-License, permitting copying and reproduction so long as the original work is given appropriate credit. Contents may not be used for commercial purposes, or adapted, remixed, transformed or built upon. (https://creativecommons.org/ licenses/by-nc-nd/4.0/)

Thieme Medical and Scientific Publishers Pvt. Ltd., A-12, 2nd Floor, Sector 2, Noida-201301 UP, India 


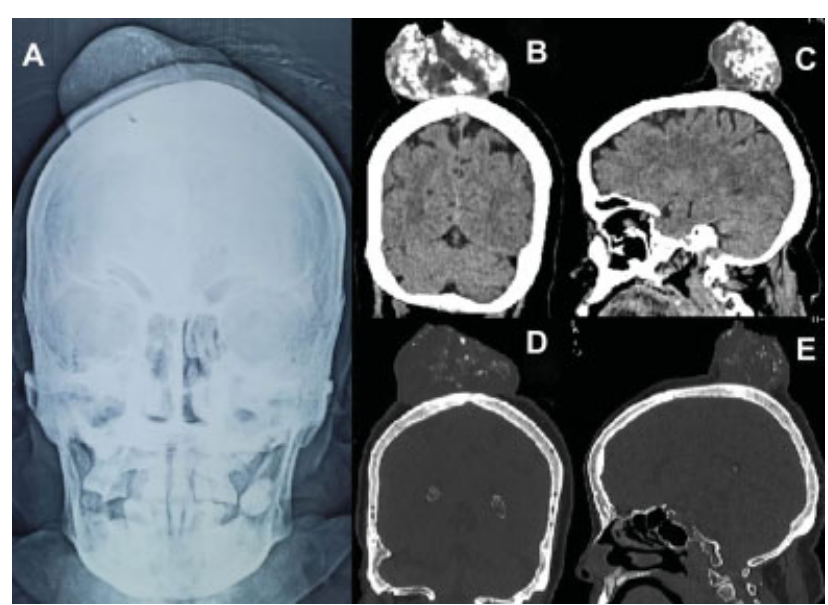

Fig. 2 Plain X-rays anteroposterior view (A) showing a scalp mass with specs of calcification inside it; (B, C) coronal and sagittal reconstructed computed tomography scans showing hypodense well demarcated mass with intralesional calcifications and (D, E) bone windows showing no calvarial erosion and that lesion is well demarcated from surrounding soft tissue.

Another 76-year-old demented patient with poor selfcare presented with an ulcerated scalp swelling with foul discharge of several years' duration of size approximately $10 \mathrm{~cm} \times 8 \mathrm{~cm} \times 6 \mathrm{~cm}$ in size ( - Fig. $3 \mathrm{~A}$ ). CT scan of brain showed a mixed density lesion with discrete areas of calcification inside it ( $\mathbf{F i g}$. 4A-C) with another minute scalp swelling in the right parietal region with calcification inside it (-Fig. 4C). Excision and primary closure was done advancing the skin margins by undermining the healthy flaps. An area in the center of the wound gave way and healed later with repeated dressings by secondary intention ( - Fig. 3B). This too was reported as a trichilemmal cyst.

\section{Discussion}

Trichilemmal cysts arise from the outer root sheath of hair follicles and are the most common tumors of the scalp. ${ }^{1,2}$ More common in women, ${ }^{1}$ they are benign, filled with keratin debris, ${ }^{2}$ and occur in $10 \%$ of the population. ${ }^{2}$ They are said to be giant if they exceed $5 \mathrm{~cm}$ in size. ${ }^{1}$ They are frequently mistaken for sebaceous cysts, ${ }^{1}$ but unlike the latter they have no central punctum, have a thicker wall, and histologically lack a granular layer ${ }^{1}$ with abrupt keratinization. ${ }^{2}$ Other differential diagnosis include lipoma, keratoacanthoma, and dermatofibrosarcoma protuberans. $^{2}$ Trichilemmal cysts usually present as smooth painless scalp swellings ${ }^{2}$ but larger lesions may present with ulceration and infection as was seen in our cases too. Trauma and inflammation may transform a trichilemmal cyst into a proliferating trichilemmal cyst that shows cellular atypia and squamous proliferation on histology, ${ }^{3}$ and these need to be radically excised as they are locally aggressive and have a potential for malignant transformation. ${ }^{3}$

Radiologically they appear as sharply defined hypodense or mixed density masses on CT scan with areas of calcification and mineralization in them that classically help to distinguish them from other scalp tumors. ${ }^{4,5}$ Unless there is malignant transformation these lesions do not show any calvarial erosion, periosteal reaction, and are well demarcated without other soft tissue infiltration, ${ }^{4,5}$ helping to differentiate them from bony erosive lesions.

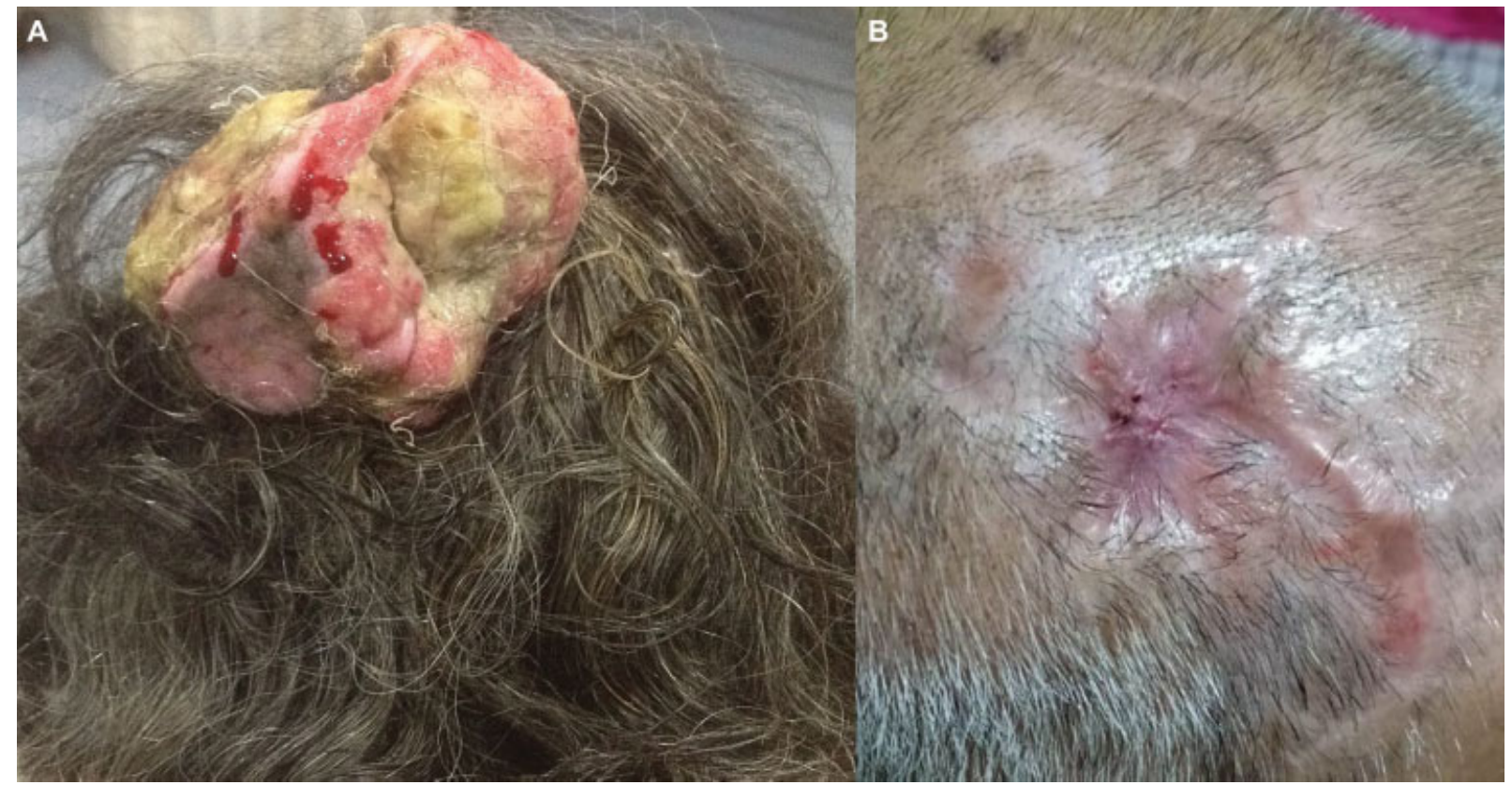

Fig. 3 Clinical photographs (A) preoperative - showing a large infected, ulcerated, lobulated scalp mass and (B) postoperative - after excision of the mass and healing partly by primary and partly by secondary intention. 


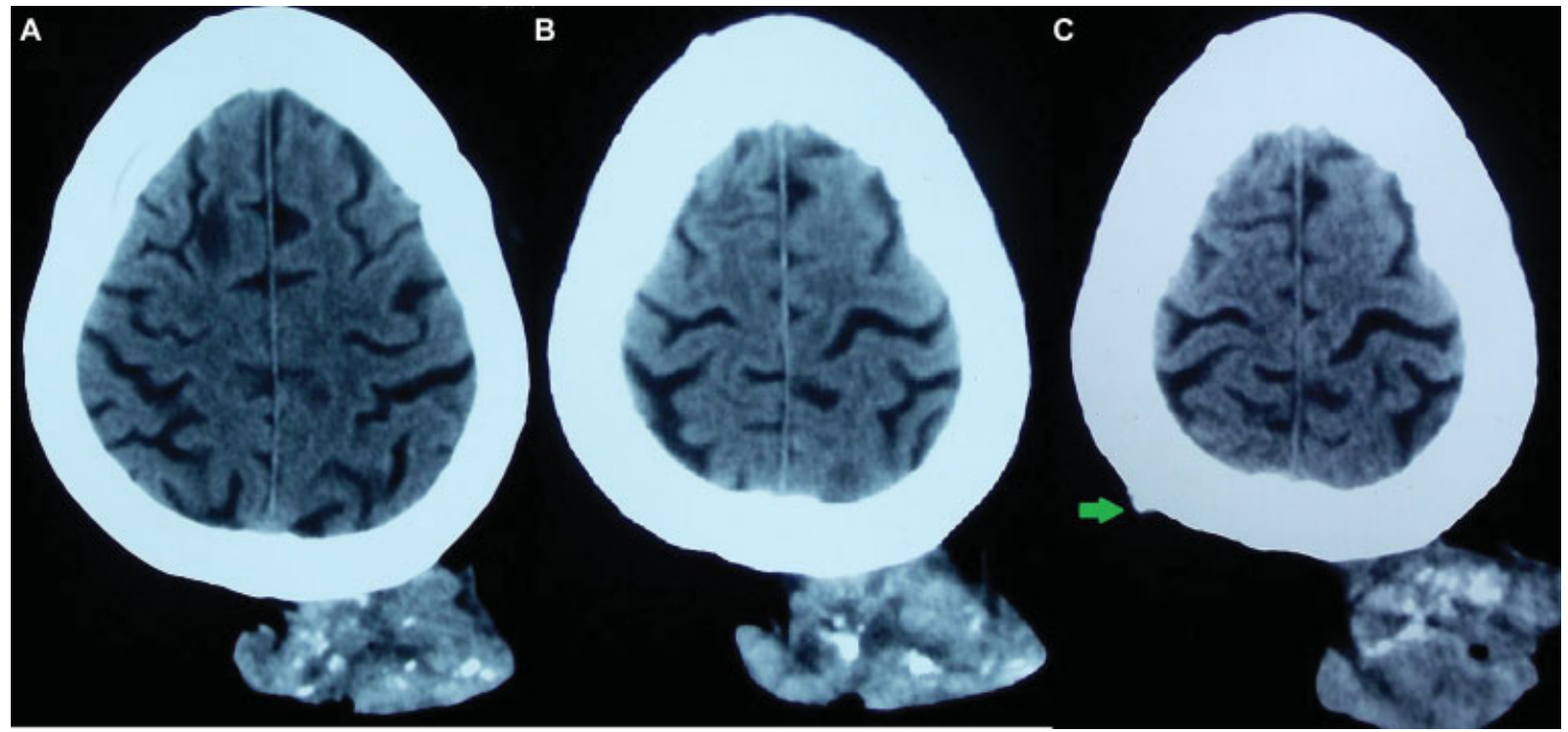

Fig. 4 Axial computed tomography scans (A-C) showing a mixed density scalp mass with patchy flecks of intralesional calcifications. There is no intracalvarial spread. An additional small lesion in the right parietal region (C) is shown (green arrow).

Neurosurgeons sometimes encounter large ulcerated scalp masses that may seem to be malignant. The presence of flecks of calcification and lack of bony involvement must make the surgeon consider the possibility of trichilemmal cysts and prompt wide excision with appropriate scalp reconstruction.

\section{Funding}

None.

Conflict of Interest

None declared.

\section{References}

1 Van M, Warbrick-Smith J, Brotto M, Hemington-Gorse S. 'You can keep your hat on': a giant forehead trichilemmal cyst. BMJ Case Rep 2017;2017:bcr2017222533

2 Tan LA, Harbhajanka A, Kasliwal MK, Nag S, Munoz LF. Giant trichilemmal cyst of the scalp. Neurol India 2016;64(02):357-358

3 Anolik R, Firoz B, Walters RF, et al. Proliferating trichilemmal cyst with focal calcification. Dermatol Online J 2008;14(10):25

4 Chang SJ, Sims J, Murtagh FR, McCaffrey JC, Messina JL. Proliferating trichilemmal cysts of the scalp on CT. AJNR Am J Neuroradiol 2006;27(03):712-714

5 Friedrich RE, Wilczak W. Multiple trichilemmal cysts of the scalp. Anticancer Res 2019;39(08):4253-4258 